\title{
Antibodies to Cellular Antigens in Sjögren's Syndrome
}

\author{
Margaret A. Alspaugh and Eng M. Tan \\ From the Division of Allergy and Immunology, Scripps Clinic and \\ Research Foundation, LaJolla, California 92037
}

\begin{abstract}
A в S T R A C T An extract of human lymphocytes from continuous cell culture was used as the antigen source to detect antibodies in sera of patients with Sjögren's syndrome (SS). Using double diffusion in agarose, $85 \%$ of a selected group of patients had precipitating antibodies. Three precipitating antigen-antibody systems were detected and were shown to be different from those described previously in other systemic rheumatic diseases. The SS precipitating antibodies were temporarily classified as precipitins A, B, and C. SS patients with sicca syndrome but without clinical rheumatoid arthritis had precipitin systems $A$ and/or $B$, and SS patients with associated rheumatoid arthritis had precipitin system C. Serum reactants were demonstrated by immunoelectrophoresis to migrate in the $\gamma$ globulin region. The precipitating activity of the serum factors was not destroyed by treatment with 2-mercaptoethanol and was not removed by absorption of rheumatoid factor from the sera. The reactivity of the lymphocyte antigens was destroyed by treatment with trypsin but not by deoxyribonuclease or ribonuclease.
\end{abstract}

\section{INTRODUCTION}

Sjögren's syndrome $(\mathrm{SS})^{1}$ is a chronic inflammatory autoimmune disease consisting of keratoconjunctivitis sicca and/or xerostomia in association with a connective tissue disease. It has been suggested that the clinical

Dr. Alspaugh is a National Institutes of Health postdoctoral trainee supported by U. S. Public Health Service Grant AI 00214.

Received for publication 23 August 1974 and in revised form 13 November 1974.

${ }^{1}$ Abbreviations used in this paper: ANA, antinuclear antibodies; DLE, discoid lupus erythematosus; IEP, immunoelectrophoresis; MCTD, mixed connective tissue disease; 2-ME, 2-mercaptoethanol; MEM, Earle's minimal essential medium; PBS, phosphate-buffered solution; PSS, progressive systemic sclerosis; RA, rheumatoid arthritis; RF, rheumatoid factor; RNP, ribonucleoprotein; SLE, systemic lupus erythematosus; sNP, solubilized deoxyribonucleoprotein; $\mathrm{SS}, \mathrm{Sjögrens}$ syndrome; Wil , a continuously growing diploid lymphocyte line obtained from a patient with hereditary spherocytosis. diagnosis of SS can be made when any two of the three features are found (1). Some of the more common connective tissue diseases found in association with SS are rheumatoid arthritis (RA), systemic lupus erythematosus (SLE), progressive systemic sclerosis (PSS), polymyositis, and polyarteritis nodosa $(1,2)$. Occasionally SS may be associated with plasma cell dyscrasia and lymphoma (3).

In the past, diagnosis of the sicca syndrome relied heavily on characteristic signs and physical tests such as the Schirmer test for keratoconjunctivitis sicca (4) and the Lashley cup test for xerostomia (5). A recent advance in the diagnosis of xerostomia is the evaluation of salivary glandular function by scintography (6). Confirmation of SS is often made by lip biopsy (6). Although these techniques are adequate, more informative tests have been sought.

Various serological tests for SS have been evaluated. In studies where sera were tested for antinuclear antibodies, $48-68 \%$ were positive by immunofluorescence on tissue substrates $(1,2)$. Nuclear staining patterns of the homogeneous, speckled, and nucleolar types have been described. However, sera from other connective tissue diseases have also shown similar patterns of nuclear staining, and SS cannot be differentiated by this test alone (7). An immunofluorescent test measuring antisalivary duct antibodies has been used to test sera from SS patients. $70 \%$ of the sera from SS-RA patients reacted, but only $10 \%$ of the sera from patients with sicca syndrome alone were positive (6). Sera from patients with SS have been tested against various tissue extracts by the complement fixation test (1). The incidence of positive tests was high when sera from patients with sicca syndrome alone were tested $(79 \%)$; however, the positives in the entire series were only $44 \%$.

Immunodiffusion in gel has been used to detect serum precipitating antibodies to tissue antigens (8-12). In these studies, extracts of human thyroid, spleen, and calf thymus nuclei have been used. A higher incidence of precipitating antibodies were reported in the sera of patients with sicca syndrome without RA (29-81\%), 
and a lower incidence of precipitins found in SS-RA $(6-32 \%)$, so that the general incidence in all SS patients varied from 31 to $43 \%$. In the above studies, the relationship of tissue autoantibodies to disease processes in SS was not clarified. With the increasing awareness that humoral autoantibodies might be involved as participating factors in the causation of tissue injury (13), this study was carried out to re-examine and characterize in greater detail the types of tissue autoantibodies in SS. We have employed extracts of a lymphocyte culture cell line as the source of tissue antigens. Patients with SS possessed autoantibodies which reacted with tissue antigens to give precipitin reactions which could be differentiated from autoantibodies found in other connective tissue diseases. In addition, antibodies of two different specificities found predominantly in SS without RA appeared to segregate from antibody of a third specificity, which was present in SS with RA and absent in SS without RA.

\section{METHODS}

Patient selection. 20 patients with SS were screened initially; however, only 18 sera were available in sufficient quantities for repeated studies. The clinical diagnosis of SS for each patient was established when at least two of the following criteria were present: keratoconjunctivitis sicca, xerostomia, or a connective tissue disease. Confirmation of the clinical diagnosis required the following laboratory evidence. The ocular tests used were either a Schirmer test (4) or a rose bengal staining test (1). The tests used for xerostomia were either salivary gland scintigraphy (5) or a lip biopsy (1) showing the abnormalities described in these reports.

The patients with SS were divided into two major categories, those with sicca complex without RA and those with sicca and associated clinical RA. The association with RA was made when symptoms and laboratory data met the criteria for classical and probable RA, as defined by the American Rheumatism Association (14). On the other hand, none of the patients with SS-sicca without RA had symptoms satisfying criteria for classical or probable RA. Other sera which were examined were obtained from 27 patients with SLE, 16 with PSS, 37 with classical and probable RA, 12 with mixed connective tissue disease (MCTD), 22 with discoid lupus erythematosus (DLE), and 22 from apparently healthy individuals. Patients with SLE met the preliminary criteria for this disease (14) and did not have features diagnostic of other connective tissue diseases. Patients were classified as having PSS on the basis of typical skin changes in the absence of polymyositis or diagnositic criteria for SLE. MCTD patients were diagnosed on the basis of classical symptoms and signs described previously (15) with the association of high titers of antibody to nuclear ribonucleoprotein (RNP). Patients with DLE had skin lesions which were considered to be compatible with this diagnosis, but, in addition, did not have other features meeting criteria for SLE (14).

Tissue extracts. A human cell line (Wil ${ }_{2}$, donated by Dr. R. Lerner, Scripps Clinic and Research Foundation, La Jolla, Calif.) was used as a source for tissue extraction. $\mathrm{Wil}_{2}$ is a continuously growing diploid lymphocyte line which was obtained from a patient with hereditary sphero- cytosis. The cells were seeded in Earle's minimal essential medium (MEM) supplemented with $2 \mathrm{mM}$ each of glutamine, sodium pyruvate, and nonessential amino acids (Flow Laboratories, Inc., Rockville, Md.). The supplemented medium also contained $10 \%$ fetal calf serum and $10 \mathrm{ml} /$ liter of antibiotic-antimycotic mixture (Grand Island Biological Co., Grand Island, N. Y.), and was adjusted to a final $\mathrm{pH}$ of 7.2 with $5.6 \% \mathrm{NaHCO}_{3}$. Cells were allowed to grow on a gyratory shaker to a concentration of $1.5 \times 10^{\circ} / \mathrm{mm}^{3}$. After this, they were centrifuged at $350 \mathrm{~g}$ for $10 \mathrm{~min}$, the packed cells resuspended in MEM without calf serum, and were centrifuged again at $900 \mathrm{~g}$ for $6 \mathrm{~min}$. The washing process was repeated three times. After the final centrifugation an equal volume of $0.25 \mathrm{M}$ sucrose with $0.004 \mathrm{M}$ calcium chloride at $\mathrm{pH} 6.2$ ( $0.01 \mathrm{M}$ phosphate) was added. The cells were then sonicated with a model W185 sonicator (Ultrasonic Systems Inc., Farmingdale, N. Y.) at a maximum output for $30 \mathrm{~s}$. The sonicate was then centrifuged at $105,000 \mathrm{~g}$ for $20 \mathrm{~min}$. The supernate was saved and used as a source of antigen. The entire procedure was performed at $4^{\circ} \mathrm{C}$.

Immunological techniques. For the demonstration of precipitating antibodies in human sera, a modification of the Ouchterlony double-diffusion method was used (16). Plastic petri dishes $(1 \times 5 \mathrm{~cm})$ containing $5 \mathrm{ml}$ of $1 \%$ agarose were used. Reactions were allowed to proceed at room temperature, and precipitin lines were observed over a period of 72 h. Early in these studies, it was apparent that reactive sera were segregating into two groups. For each group of precipitating sera, a prototype serum was chosen and used as the reference serum at a dilution which gave optimum precipitin lines with lymphocyte extract. Sera were analyzed in double diffusion by placing them in wells adjacent to reference sera and by examination of precipitin lines for identity or nonidentity with these reference sera. In cases where precipitin lines were weak, manipulation of the system such as changing the dilution of sera or the concentration of antigens in extract produced stronger precipitin lines and allowed definite identification with reference sera.

As a result of previous studies, other reference sera were available which contained antibodies to DNA, solubilized deoxyribonucleoprotein (sNP), streptomycin (Sm) antigen, RNP antigen, and nucleolar RNA (17). Antibodies to DNA, sNP, and Sm antigens are present primarily in SLE, antibody to RNP in SLE and the MCTD, and antibody to nucleolar RNA in scleroderma and SS (17). With sera containing precipitating antibodies to $\mathrm{Wil}_{2}$ extract, it was possible to show that the antibodies in SS sera were not identical to those previously described for other connective tissue diseases.

Noble agar $(1 \%)$ in 0.05 ionic strength barbital buffer, $\mathrm{pH} 8.5$, was used for immunoelectrophoresis (IEP). $\mathrm{Pa}-$ tients' sera were placed in the center well and electrophoresed for $1.5 \mathrm{~h}$ at $8 \mathrm{~mA} / \mathrm{slide}$. Lymphocyte extract was added to one trough and antiwhole human serum added to the second trough. Reaction was allowed to proceed at room temperature. Precipitin lines were observed over a period of $72 \mathrm{~h}$. Appropriate control sera and antigens were treated in the same manner.

Enzymatic treatment of extracts. Ribonuclease (RNase), deoxyribonuclease (DNase), and trypsin were obtained from Worthington Biochemical Corp., Freehold, N. J. They were first tested in the appropriate buffers to determine that the enzymes were fully active in these buffers (18). These enzymes were employed in the treatment of lymphocyte extracts. The ratios by weight of enzyme to substrate used were as follows: RNase to substrate $1: 1,1: 5$, and $1: 30$, 
DNase to substrate $1: 2$ and $1: 50$, and trypsin to substrate $1: 20$ and $1: 100$. All digestions were incubated at $37^{\circ} \mathrm{C}$ for $2 \mathrm{~h}$. Trypsin digestions were performed in $0.04 \mathrm{M}$ Tris buffer at $\mathrm{pH} 8.1$ in the presence of $0.0115 \mathrm{M}$ calcium ions. DNase digestions were performed in $0.01 \mathrm{M}$ phosphate buffered, $0.15 \mathrm{M} \mathrm{NaCl}$ at $\mathrm{pH} 7.4$ (PBS) in the presence of $0.006 \mathrm{M}$ magnesium ions. The RNase digestions were performed also in PBS at $\mathrm{pH}$ 7.4. The treated extracts were then titered out against prototype sera in the Ouchterlony technique and compared with controls.

Chemical treatment of patients' sera. Patients' sera were treated with 2-mercaptoethanol (2-ME). Reactants were added to each other at volume of $1: 1$ leaving the final molarity of $2-\mathrm{ME}$ at $0.1 \mathrm{M}$ and the sera at a dilution of $1: 2$. After mixing, the reactants were left at room temperature for $15 \mathrm{~h}$ (19) before testing by the Ouchterlony technique. The treated sera were then titered out against the lymphocyte extract and compared with controls.

Absorption of rheumatoid factor from patients' sera. Human $\gamma$-globulins (fraction II) (Miles Laboratories Inc., Miles Research Div., Elkhart, Ind.) at a concentration of $25 \mathrm{mg} / \mathrm{ml}$ in PBS were heated at $63^{\circ} \mathrm{C}$ for $20 \mathrm{~min}$. The aggregated globulins were then lyophilized and added to sera at $15 \mathrm{mg} / \mathrm{ml}$ and left overnight at $4^{\circ} \mathrm{C}$. The samples were then centrifuged at $36,000 \mathrm{~g}$ for $20 \mathrm{~min}$, and the supernate was tested for residual rheumatoid factor (RF) by the latex agglutination test.

Chemical determinations. Protein concentrations were determined by the Lowry procedure (20). DNA was determined by a modification of the diphenylamine reaction (21), and RNA was determined by the orcinol reaction (22).

\section{RESULTS}

Characterization of crude extracts. Some of the characteristics of the extracts have been determined by chemical methods. After the cells had been sonicated in a sucrose-calcium chloride solution, the protein concentration was $40 \mathrm{mg} / \mathrm{ml}$. After centrifugation at $105,000 \mathrm{~g}$,



FIGURE 1 Immunodiffusion study showing the three different precipitin systems found in SS sera reactive with $\mathrm{Wil}_{2}$. Serum SS was from a patient with sicca syndrome which produced two precipitins (A and B). Serum SS-RA was from a patient with sicca syndrome and RA which produced one precipitin system with the extract and showed complete nonidentity with the precipitins of the SS serum.

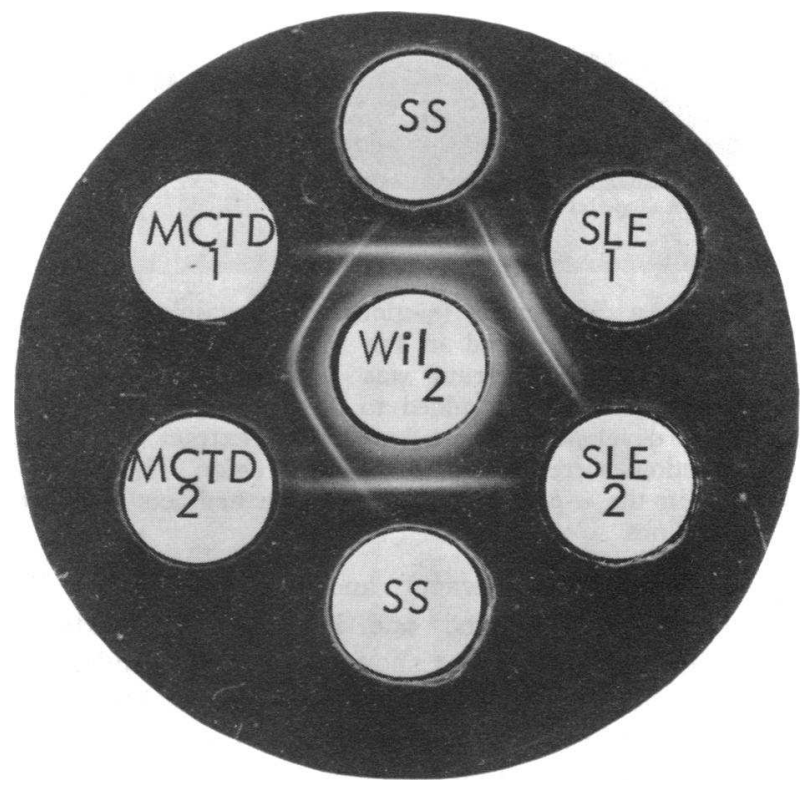

FIGURE 2 Immunodiffusion study showing nonidentity of precipitating systems in SS and precipitins in other systemic rheumatic diseases. SLE1 was serum with antibody to $\mathrm{Sm}$ antigen (the sharper of the two precipitin lines and closest to tissue extract well). MCTD1 and MCTD2 were sera from MCTD with precipitating antibody to RNP. This precipitin line like the $\mathrm{Sm}$ precipitin was not related immunologically to the SS lines. SLE2 contained precipitating antibody to sNP and was nonreactive because this antigen was not present in $\mathrm{Wil}_{2}$ extract.

the supernate contained $25 \mathrm{mg} / \mathrm{ml}$ protein, $5.3 \mathrm{mg} / \mathrm{ml}$ RNA, and $0.018 \mathrm{mg} / \mathrm{ml} \mathrm{DNA}$. This supernate was used as a source of antigen for detecting antibodies in patients' sera by double diffusion in agarose.

Preliminary screening of patients' sera by Ouchterlony technique. The sera from $20 \mathrm{SS}$ patients were tested against lymphocyte extracts containing $25 \mathrm{mg} / \mathrm{ml}$ protein in the Ouchterlony technique. 17 of these were positive $(85 \%)$. When the SS sera which were previously positive were titered out against the undiluted extract, precipitin lines were observed with some sera at $1 / 512$ dilution. When the extract was diluted out and tested against seven representative SS sera, the end points ranged between $5 \mathrm{mg} / \mathrm{ml}$ and $1.2 \mathrm{mg} / \mathrm{ml}$ of protein. Some of the extract was dialyzed against $\mathrm{PBS}$ at $\mathrm{pH}$ 7.4 and lyophilized. The lyophilized material was as reactive as unlyophilized extract and remained stable for at least $2 \mathrm{mo}$ at $4^{\circ} \mathrm{C}$.

Fig. 1 illustrates the three precipitin systems found in sera from patients with SS. Serum SS, which contained precipitins $\mathrm{A}$ and $\mathrm{B}$, was from a patient with sicca syndrome. The serum labeled SS-RA was from a patient with sicca syndrome and RA which contained precipitin C. Wil extract was in the upper well. Serum SS produced two lines with extract, precipitin system A 


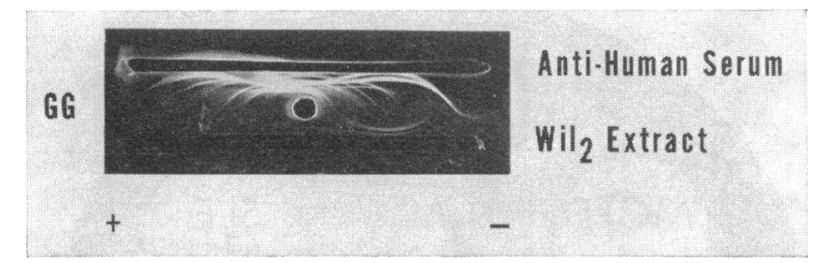

FIGURE 3 An SS serum ( $\gamma$-globulin) containing precipitins $\mathrm{A}$ and $\mathrm{B}$ was placed in the center well and electrophoresed. Antihuman serum was then added to the top trough and $\mathrm{Wil}_{2}$ extract added to the bottom trough. Two precipitins developed against lymphocyte extract and both these reactions were located in the IgG region. The irregular lines in the $\alpha$ - $\beta$-globulin region were artifacts and not precipitin lines.

(closer to the $\mathrm{Wil}_{2}$ extract), and precipitin system $\mathrm{B}$. Serum SS-RA produced one line with the extract (precipitin system $C$ ) that showed complete nonidentity with systems A or B. It was important to establish that the precipitin systems observed with SS sera were different from precipitating antibodies described in other connective tissue diseases. This was performed by using previously analyzed sera containing known antibodies, and such a study is shown in Fig. 2. Serum SS was from a patient with $\mathrm{SS}$ and reacted with $\mathrm{Wil}_{2}$ to give the two precipitin systems described in Fig. 1. Precipitin system A was much stronger than precipitin system $B$ because the two tissue antigens were present in the extract in different concentrations, with A predominating over B. With this particular SS serum, antibody to the $A$ antigen was present in higher titer than antibody to the B antigen. SLE1 was serum from a patient with SLE and gave two precipitin lines with $\mathrm{Wil}$, the sharper line closer to the antigen well has been identified in previous studies as the Sm system. The second line further from the antigen well has not been identified. It was clear that the Sm system of SLE was dif-

TABLE I

Precipitin Systems Found in Patients' Sera

\begin{tabular}{|c|c|c|c|c|c|}
\hline \multirow[b]{2}{*}{ Patient } & \multirow[b]{2}{*}{ Disease } & \multirow[b]{2}{*}{ Number of systems } & \multicolumn{3}{|c|}{ Precipitins } \\
\hline & & & $\mathbf{A}$ & B & $\mathrm{C}$ \\
\hline G. T. & ss & 1 & + & - & - \\
\hline A. $Z$. & ss & 2 & + & + & - \\
\hline G. G. & ss & 2 & + & + & - \\
\hline J. M. & ss & 2 & + & + & - \\
\hline T. H. & ss & 2 & + & + & - \\
\hline P. C. & ss & 1 & - & + & - \\
\hline M. F. & ss-JRA & 1 & + & - & - \\
\hline M. C. & ss-PSS & 2 & + & - & + \\
\hline P. F. & ss-Raynauds & 2 & + & - & + \\
\hline M. M. & ss-RA & 1 & - & - & + \\
\hline J. C. & ss-RA & 1 & - & - & + \\
\hline H. O. & ss-RA & 1 & - & - & + \\
\hline A. D. & ss-RA & 1 & - & - & + \\
\hline M. G. & ss-RA & 1 & - & - & + \\
\hline E. R. & ss-RA & 1 & - & - & + \\
\hline
\end{tabular}

ss, sicca syndrome; JRA, juvenile rheumatoid arthritis.
TABLE II

Incidence of Antibodies to $A, B$, or $C$ in Connective Tissue Diseases

\begin{tabular}{lrrrr}
\hline & \multirow{2}{*}{$\begin{array}{c}\text { Positive/ } \\
\text { tested }\end{array}$} & & \multicolumn{3}{c}{ Precipitins } \\
\cline { 3 - 5 } & A & B & C \\
\hline RA & $24 / 37$ & 0 & 0 & $24(65 \%)$ \\
MCTD & $0 / 12$ & 0 & 0 & 0 \\
DLE & $0 / 22$ & 0 & 0 & 0 \\
PSS & $0 / 16$ & 0 & 0 & 0 \\
SLE & $2 / 27$ & 0 & 0 & 2 \\
NHS & $1 / 22$ & 0 & 0 & 1 \\
\hline
\end{tabular}

ferent from the systems in SS. MCTD1 and MCTD2 were two sera from two patients with MCTD. They also reacted with $\mathrm{Wil}_{2}$ extract, and this system has been identified as the RNP system of MCTD. The latter was also not identical immunologically with the SS systems. SLE2 was a serum with precipitating antibody to deoxyribonucleoprotein but did not react with Wile, illustrating that the latter extract did not contain soluble deoxyribonucleoprotein. Studies not illustrated here showed that the SS-precipitating systems were not related to precipitating antibodies to native or denatured DNA. Similar studies were also conducted to analyze precipitin system $\mathrm{C}$ which showed that it was not related to precipitating systems involving $\mathrm{Sm}, \mathrm{RNP}, \mathrm{sNP}$, and native and denatured DNA.

Of 17 sera which were positive in early screening studies, only 15 remained for identification of precipitin systems. Although only a limited number of SS sera were examined, the results appeared to show that precipitins A and B were present mainly in patients with sicca syndrome, and precipitin $\mathrm{C}$ was present in patients with SS-RA (see Table I). It was noted that the patient with sicca and juvenile RA had precipitin A, and the two patients with either SS-PSS or SS-Raynaud's had precipitins $\mathrm{A}$ and $\mathrm{C}$.

Sera from patients with diseases other than SS were also studied for precipitins A, B, or C. The only group with a significant incidence was the RA group in which $65 \%$ of the patients' sera contained precipitin C, suggesting that the presence or absence of RA may influence which precipitins were detected (Table II).

IEP of patients' sera. IEP was performed to determine if the serum factor(s) reacting with tissue antigens could be identified by this technique. Five sera (three from sicca patients and two from SS-RA patients) with the highest titers of serum precipitins in double diffusion also showed precipitins by IEP and in all five cases; serum precipitins were located in the $\gamma$-globulin region, and the precipitin arcs had the characteristic location and curvature of IgG. A representative example (serum GG) is shown in Fig. 3, where 
serum was electrophoresed in the center well and developed with antiwhole human serum in the top trough and with tissue extract in the bottom trough. Serum $\gamma$-globulin demonstrated two precipitin arcs with gamma mobility and in double diffusion; this serum had been one of the reference sera with the two precipitin systems $A$ and $B$. The other two sera, containing precipitins $A$ and $B$, produced two arcs in IEP, but the two sera from patients with SS-RA, containing precipitin C, produced one arc. Other sera with lower titers of precipitins were also tested by IEP, but precipitin arcs were not always detected, a feature which was thought to be related to the lower sensitivity of the IEP technique compared to the Ouchterlony technique.

$2-M E$ treatment of patients' sera. Sera from five patients with SS were treated with 2-ME, titered against extracts, and the end points compared with controls. All five sera tested were resistant to 2-ME. Three of the sera were from SS patients with sicca syndrome which contained precipitins $\mathrm{A}$ and $\mathrm{B}$. The other two sera were from patients with SS-RA which contained precipitin $\mathrm{C}$.

Effects of physical or biochemical treatment of extracts. Some of the physiobiochemical characteristics of individual antigens have been determined. The extract was treated with RNase, DNase, and trypsin and was tested against various sera by the Ouchterlony technique. In these studies sera from two patients were used to represent systems $A$ and $B$, and two sera from SS-RA patients were used to present system $C$ in the Ouchterlony technique. All the antigens in the $\mathrm{A}, \mathrm{B}$, and $\mathrm{C}$ systems were rendered nonreactive by treatment with trypsin at both enzyme-substrate ratios tested (1:20 and $1: 100)$, but were unaffected by treatment with nuclease enzymes at all ratios tested. The antigens were not affected by $2-\mathrm{ME}$ treatment or by heating at $56^{\circ} \mathrm{C}$ for $1 \mathrm{~h}$.

Absorption of sera with aggregated IgG. Sera from seven patients with sicca syndrome alone and sera from six patients with SS-RA were tested by the Ouchterlony technique against heat-aggregated IgG. Sera from patients with sicca syndrome were nonreactive with aggregated IgG. Five of the six sera from SS-RA patients reacted. All five had high-titer $R F$ by the latex agglutination test. Sera from these patients with SS-RA were absorbed with aggregated IgG until RF was reduced from a titer of 2,560 to 20 or less. The absorbed sera were negative for precipitins to aggregated IgG, but were still positive against the lymphocyte extract, demonstrating that the precipitin reaction of the $\mathrm{C}$ system was not due to RF.

\section{DISCUSSION}

In the present studies, we have described three types of precipitating autoantibodies in the sera of patients with
SS. With the limited number of SS sera examined, it appeared that two types of precipitating antibodies, temporarily identified as the $\mathrm{A}$ and $\mathrm{B}$ systems, were present predominantly in SS without RA, whereas the third type of precipitating antibody was present in SS with RA and not in SS without RA. This segregation of precipitating antibodies has been substantiated in a study of a larger number of SS sera and will be reported in a later communication. ${ }^{2}$ In these studies 56 patients with sicca syndrome and 33 patients with SS-RA were tested. $76 \%$ of the SS-RA patients had precipitin $\mathrm{C}$ and less than $9 \%$ had precipitins $\mathrm{A}$ and/or B. On the other hand, more than $79 \%$ of the patients with sicca syndrome had $\mathrm{A}$ and/or $\mathrm{B}$, whereas less than $5 \%$ had precipitin C. It should be noted that in studies by previous investigators, primarily those of Anderson, Gray, Beck, and Kinnear (9), two types of precipitating antibodies, $S_{1} D$ and $S_{1} T$, were described. It would appear to be more than coincidental that these workers also found that the two antibodies were present in SS without RA but not in other forms of SS. They observed that one of their antigens, $\mathrm{SiT}$ was destroyed by heating at $56^{\circ} \mathrm{C}$ for $1 \mathrm{~h}$ and by digestion with trypsin, but $S_{1} D$ was not affected by either treatment. In our studies, both the $A$ and $B$ antigens were stable to heat but both were destroyed by digestion with trypsin. At this time, it is difficult to explain the discrepancies especially if the two antigens were presumed to be identical. However, we hope to obtain answers to these questions by exchange of sera and reagents with these workers.

In contrast to previous workers who have found low incidence of precipitins to tissue extracts in SS with $\mathrm{RA}$, we found precipitins to the $\mathrm{C}$ system in SS-RA in high incidence not only in the few selected sera reported here but also in a larger series. ${ }^{2}$ This difference may be due in part to the fact that our extracts were obtained from tissue culture cells, a procedure which permitted immediate extraction of tissue antigens without undergoing autolysis. Alternatively, the $\mathrm{C}$ antigen might be unique to lymphocytes or to certain tissue culture cell lines, possibilities which we have not investigated. In any case, an interesting observation that emerged was that serologically, SS-RA could be differentiated from the pure sicca syndrome or SS without RA, suggesting that these two forms of SS might not necessarily be closely related. This was also suggested by MacSween et al. (23) who proposed that a subclinical form of SS might be present in some patients with RA. This proposal was based on the finding that there was a high incidence of salivary duct antibody in SS-RA but a low incidence in SS without RA. Further work

${ }^{2}$ Alspaugh, M. A., N. Talal, and E. M. Tan. Unpublished observations. 
showing differences in the forms of SS were studies $(24,25)$ that peripheral lymphocytes from SS-RA responded less well to mitogenic stimulation with phytohemagglutinin, dinitrochlorobenezene, tetanus toxoid, and streptolysin, than lymphocytes from SS without RA.

The intracellular location of the tissue antigens which react with SS sera has not been clearly defined. In the study of Bloch, Buchanan, Wohl, and Bunim, the incidence of antinuclear antibodies (ANA) in a large series of SS patients was $68 \%$ (1). Studies in this laboratory have shown a $59 \%$ incidence of ANA in SS, but in these same patients, $86 \%$ had precipitins $\mathrm{A}, \mathrm{B}$, or $\mathrm{C}$. This suggests that at least one or more of the precipitins may be antibodies against cytoplasmic or nonnuclear components. If normal human leukocytes were used as substrate for ANA, in addition to nuclear staining, there was significant cytoplasmic staining with sera which gave positive precipitin reactions, further suggesting that cytoplasmic antigens might be involved in some of the precipitin systems described here.

It is becoming clear from many recent reports that autoantibodies of certain specificities are segregated in their distribution. For example, antibodies to doublestranded DNA and to the Sm nuclear antigen were detected predominantly in $\operatorname{SLE}(17,26)$, and antibodies to nuclear RNP were detected in the MCTD as well as $\operatorname{SLE}(15,17,27)$. It would thus be important to be able to define the antigenic or biochemical specificities of the many autoantibodies found in certain diseases, since there might be distinct profiles of autoantibody specificities for each disease. The usefulness of such an approach has already become apparent in SLE where tests for anii-DNA antibodies have helped in diagnosis, as well as in management, of SLE. Furthermore, these and other studies on the specificities of autoantibodies in SS might be anticipated to lead to investigations concerning the relationship of these autoantibodies to disease processes. At the present time, it is not known whether these antibodies participate in causing tissue injury or are epiphenomena of previous cellular damage from other causes. In any event it is clear that autoantibodies in SS react with cellular antigens which are immunochemically different from cellular antigens reacting with autoantibodies in other systemic rheumatic diseases. The processes which lead to the production of autoantibodies of such diverse immunochemical specificities and the reasons for the segregation of some types of autoantibodies in certain diseases are not understood at the present time.

\section{ACKNOWLEDGMENTS}

We are grateful to Doctors J. Johnson, L. Jacobs, P. Hench, and R. McKendry for donating sera and to Ms. C. Tifft for excellent technical assistance.

This work was supported by U. S. Public Health Service Grant AM 12198.

\section{REFERENCES}

1. Bloch, K. J., W. W. Buchanan, M. J. Wohl, and J. J. Bunim. 1965. Sjögren's syndrome: a clinical, pathological, and serological study of sixty-two cases. Medicine (Baltimore). 44: 187-231.

2. Whaley, K., J. Webb, A. McAvoy, G. R. V. Hughes, P. Lee, R. N. M. MacSween, and W. W. Buchanan. 1973. Sjögren's syndrome. II. Clinical associations and immunological phenomena. Q. J. Med. 42: 513-548.

3. Talal, N., and J. J. Bunim. 1964. The development of malignant lymphoma in the course of Sjögren's syndrome. Am. J. Med. 36: 529-540.

4. Schirmer, O. 1903. Studien zur physiologie and pathologie der tränenabsonderung und tränenabfuhr. Graefe Arch. Ophthal. 56: 197-291.

5. Schall, G. L., L. G. Anderson, R. O. Wolf, J. R. Herdt, T. M. Tarpley, Jr., N. A. Cummings, L. S. Zeiger, and N. Talal. 1971. Xerostomia in Sjögren's syndrome: evaluation by sequential salivary scintigraphy. JAMA J. Am. Med. Assoc. 216: 2109-2116.

6. Cummings, N. A., G. L. Schall, R. Asofsky, L. G. Anderson, and N. Talal. 1971. Sjögren's syndrome-newer aspects of research, diagnosis, and therapy. Ann. Intern. Med. 75 : 937-950.

7. Tan, E. M. 1967. Relationship of nuclear staining patterns with precipitating antibodies in systemic lupus erythematosus. J. Lab. Clin. Med. 70: 800-812.

8. Jones, B. R. 1958. Lacrimal and salivary precipitating antibodies in Sjögren's syndrome. Lancet. 2: 773-776.

9. Anderson, J. R., K. G. Gray, J. S. Beck, and W. F. Kinnear. 1961. Precipitating autoantibodies in Sjögren's disease. Lancet. 2: 456-460.

10. Anderson, J. R., K. G. Gray, J. S. Beck, W. W. Buchanan, and A. J. McElhinney. 1962. Precipitating autoantibodies in connective tissue diseases. Ann. Rheum. Dis. 21 : 360-369.

11. Beck, J. S., J. R. Anderson, and K. J. Bloch. 1965. Antinuclear and precipitating auto-antibodies in $\mathrm{Sjö-}$ gren's syndrome. Ann. Rheum. Dis. 24: 16-22.

12. Talal, N., E. Zisman, and P. Schur. 1968. Renal tubular acidosis, glomerulonephritis, and immunologic factors in Sjögren's syndrome. Arthritis Rheum. 11: 774-786.

13. Koffler, D., P. H. Schur, and H. G. Kunkel. 1967. Immunological studies concerning the nephritis of systemic lupus erythematosus. J. Exp. Med. 126: 607-623.

14. Primer on the Rheumatic Diseases. Criteria for Diagnosis and Classification of Rheumatic Diseases. 1973. JAMA J. Am. Med. Assoc. 224 (Suppl.) : 137-139.

15. Sharp, G. C., W. S. Irvin, E. M. Tan, R. G. Gould, and H. R. Holmen. 1972. Mixed connective tissue disease-an apparently distinct rheumatoid disease syndrome associated with specific antibody to an extractable nuclear antigen (ENA). Am. J. Med. 52: 148-159.

16. Tan, E. M., and H. C. Kunkel. 1966. Characteristics of a soluble nuclear antigen precipitating with sera of patients with systemic lupus erythematosus. J. Immunol. 96: 464-471.

17. Tan, E. M., J. D. Northway, and J. L. Pinnas. 1973. The clinical significance of antinuclear antibodies. Postgrad. Med. 54: 143-150.

18. Worthington Enzyme Manual. 1972. Worthington Biochemical Corp., Freehold, N. J.

19. Kim, Y. B., S. G. Bradley, and D. W. Watson. 1964. Characterization of early $19 \mathrm{~S}$ and late $7 \mathrm{~S}$ immunoglobulins into mouse. J. Immunol. 93: 798-806. 
20. Lowry, O. H., N. J. Rosebrough, L. Farr, and R. J. Randall. 1951. Protein measurement with a Folin phenol reagent. J. Biol. Chem. 113: 265-275.

21. Giles, K. W., and A. Myers. 1965. An improved diphenylamine method for the estimation of deoxyribonucleic acid. Nature (Lond.). 206: 93.

22. Dische, Z. 1966. The Nucleic Acids. E. Chargaff and J. N. Davidson, editors. Academic Press, Inc., New York.

23. MacSween, R. N. M., R. B. Goudie, J. R. Anderson, E. Armstrong, M. A. Murray, D. K. Mason, M. K. Jasani, J. A. Boyle, W. W. Buchanan, and J. Williamson. 1967. Occurrence of antibody of salivary duct epithelium in Sjögren's disease, rheumatoid arthritis, and other arthritides. A clinical and laboratory study. Ann. Rheum. Dis. 26: 402-411.
24. Leventhal, B. G., D. S. Waldorf, and N. Talal. 1967. Impaired lymphocyte transformation and delayed hypersensitivity in Sjögren's syndrome. J. Clin. Invest. 46: 1338-1345.

25. Whaley, K., A. C. A. Glen, R. N. M. MacSween, S. Deodhar, W. C. G. Nuki, J. Williamson, and W. W. Buchanan. 1971. Immunological responses in Sjögren's syndrome and rheumatoid arthritis. Clin. Exp. Immunol. 9 : 721-732.

26. Koffler, D., V. Agnello, and H. G. Kunkel. 1971. Systemic lupus erythematosus: prototype of immune complex nephritis in man. J. Exp. Med. 134(Suppl.): 169179.

27. Mattioli, M., and M. Reichlin. 1971. Characterization of a soluble nuclear ribonucleoprotein antigen reactive with SLE sera. J. Immunol. 107 : 1281-1290. 